\title{
Comparison between four treatment modalities for active myofascial triggers points
}

\author{
Atef Fouda \\ School of Oral and Dental medicine, Cairo University, Giza 12411, Egypt. \\ Address for correspondence: Dr. Atef Fouda, Faculty of Oral and Dental Medicine, Cairo University, Gamaa Street, Giza 12411, Egypt. \\ E-mail: atef.fouda@dentistry.cu.edu.eg
}

\begin{abstract}
Aim: The study aimed at the painful trigger points (TrPs) for the purpose of ablating muscle spasms and restoring normal muscle length to find the most effective treatment for alleviating pain and improving mouth range of motion in patients with myofascial pain dysfunction. Methods: We enrolled 72 patients with pain and reduced mouth opening due to temporomandibular joint dysfunction. Patients assigned to four groups and four treatment modalities used to treat myofascial TrPs pain. We used mean and standard deviation values. The Mann-Whitney $U$-test was used to compare the two groups. The Wilcoxon signed-rank test was used to study the changes by the time in mean pain scores. The Student's $t$-test was used to compare maximum mouth opening (MMO) groups. Then paired $t$-test was also used to study the changes of time in an MMO. Results: The results showed that pulsed electromagnetic field (PEMF) therapy is the most effective treatment modality regarding for pain relief. Both the anesthesia and PEMF groups showed a reduction in mean pain scores throughout all follow-up periods, and a statistically significant increase in mean MMO. Conclusion: The findings suggest that PEMF is the most effective treatment for alleviating pain and improving mouth range of motion in patients with myofascial pain.
\end{abstract}

Key words:

Low-level laser therapy, myofascial pain, pulsed electromagnetic field, temporomandibular joint dysfunction, trigger points

\section{INTRODUCTION}

Myofascial pain dysfunction syndrome (MPDS) is the most common cause of facial pain. Patients with MPDS experience pain, restricted jaw movements, and masticatory muscle tenderness. ${ }^{[1]}$ Psychological factors, occlusion imbalance, and parafunctional habits have been cited as its most important underlying causes. ${ }^{[2]}$

\begin{tabular}{|l|l|}
\hline \multicolumn{2}{|c|}{ Access this article online } \\
\hline Quick Response Code: & Website: \\
\hline & www.parjournal.net \\
\cline { 2 - 2 } & \\
\hline & DOI: \\
\hline
\end{tabular}

Myofascial pain dysfunction syndrome is a regional muscular pain syndrome characterized by the presence of hypersensitive points known as "trigger points" (TrPs) in one or more muscle and/or connective tissue. The masseter muscles and to a lesser extent temporalis muscles are frequently involved in MPDS. ${ }^{[3]}$

It has been suggested that certain nerve endings in the muscle tissue become sensitized by allergenic substances, which create a localized zone of hypersensitivity. ${ }^{[4-6]}$

Trigger points are discrete, focal, hyperirritable areas located in taut bands of skeletal muscle. The TrPs are painful upon compression and can induce referred pain, referred tenderness, motor dysfunction, and autonomic phenomena. ${ }^{[7]}$

Myofascial trigger points (MTrPs) are classified as being active or latent, according to their clinical characteristics. 
An active TrPs causes pain at rest, while a latent TrPs does not cause spontaneous pain, but may restrict movement or cause muscle weakness. ${ }^{[8]}$

Thus, a typical TrPs is characterized by the presence of discrete focal tenderness within a palpable taut band of skeletal muscle, which generates both referred regional pain and a local twitch response (LTR). TrPs are associated with referred pain in MPDS, while tender points in comparison are associated with pain at the site of palpation only and occur in the insertion zones of muscles, not in the taut bands in the muscle belly. ${ }^{[9]}$

Several histopathologic mechanisms have been proposed to account for the development of TrPs and subsequent pain patterns. Many researchers concur that acute trauma or repeated microtrauma may lead to the development of a TrPs. ${ }^{[10]}$

In the head and neck regions, MPDS presents as tension headaches, tinnitus, temporomandibular joint pain, and in rare cases visual symptoms. ${ }^{[11]}$

Palpation of a hypersensitive bundle or nodule of muscle fiber of harder than normal consistency is the physical finding most often associated with a TrPs. Localization of a TrPs is based on the physician's sense of feel, assisted by patient expressions of pain and by visual and palpable observations of LTR. ${ }^{[7]}$

The diagnosis of temporomandibular joint dysfunction (TMJD) requires a skilled clinician with training and experience in recording a patient's histories, conducting thorough examinations, and identifying MTrPs. Diagnosis confirmed by the occurrence, at least of a taut band, and pain felt by the patient when pressure is applied to a tender nodule. ${ }^{[12]}$

Most treatment methods for myofascial pain are empirical and aim to identify painful TrPs for the purpose of ablating muscle spasm and restoring normal muscle length, function and strength.

Both psychological and physical treatments are necessary to overcome MPDS. ${ }^{[1]}$ Conservative treatments are generally useful for alleviating pain and preventing dysfunction. Dentists use different therapies such as pharmacologic treatments, which include analgesics, muscle relaxants, antidepressants, neuroleptics, or nonsteroidal anti-inflammatory drugs. ${ }^{[13]}$

Alternative treatment modalities include acupuncture, massage, acupressure, ultrasonography, application of heat or ice, diathermy, transcutaneous electrical nerve stimulation, ethyl chloride spray, and stretching techniques.

Other methods of treatment include: dry needling; TrPs injections with local anesthetic, saline, or steroid; occlusal splints; biofeedback; and physiotherapy. ${ }^{[2]}$
Treatment modalities that have been used to inactivate of MTrPs include: interrupting the pain cycle by penetrating the MTrPs with a needle; injecting local anesthetic or saline; and applying a cooled spray to the skin, followed by muscle stretching. ${ }^{[11]}$

Low-level laser therapy (LLLT), ultrasound and electro galvanic stimulation can also be useful in managing MTrPs. ${ }^{[14,15]}$

Modern dental practice encompasses low-level lasers therapy to accelerate tissue healing, alleviate pain, reduce inflammation and physiotherapy in the orofacial region. Low-level laser application plays an important role in the treatment of most musculofacial disorders and facial pain. ${ }^{[16-19]}$

Laser light is energy that results from stimulated emission of radiation. The laser light biostimulation of structural tissue can be increased to an energy level that creates chemical reactions. It stimulates protein synthesis, phagocytic activities and aerobic energy to induce anti-inflammatory, analgesic, and tissue repair effects. ${ }^{[20]}$ The laser type is determined by the wavelength of the light based on the solid state aggregation of the energized material. Many types of lasers have been used, e.g., helium: neon, gallium-aluminum-arsenide (Ga-Al-As), neodymium-doped yttrium aluminum garnet, and carbon dioxide. ${ }^{[21]}$

Gallium-aluminum-arsenide is a diode laser with a wavelength of $780 \mathrm{~nm}$. Some studies have shown that Ga-Al-As lasers have positive effects, ${ }^{\mid 22,23]}$ including acceleration of wound healing and pain reduction, ${ }^{[24,25]}$ although many studies have shown no positive effect. ${ }^{[26,27]}$

Laser photobiomodulation is a low-cost, noninvasive treatment that has been widely used for treating a diverse range of conditions, including muscle/joint conditions. It has been used frequently in physical therapy practice for pain relief and tissue regeneration, and has been proven as beneficial in treating TMJD. Various studies have confirmed therapeutic effects including are anti-inflammatory, analgesic and cell activity modulating actions. $^{[28-30]}$

Dry needling has been found to be as effective as drug injection for the relief of pain in muscles and connective tissue. In the treatment of TrPs for persons with myofascial pain syndrome, in which an acupuncture needle is inserted into the skin and muscle directly into a MTrPs. ${ }^{[31]}$

A MTrPs consists of multiple contraction knots, which are related to the production and maintenance of the pain cycle. Accurate dry needling of a MTrPs elicits a LTR, which is an involuntary spinal cord reflex in which the muscle fibers in a taut band of skeletal muscle contraction. An LTR indicates the proper placement of the needle in a TrPs. Research has shown that dry needling 
that elicits LTRs improves treatment outcomes. It has been suggested that A-delta nerve fibers are activated, as the needle pierces the skin, resulting in inhibition of muscular C-nerve fibers that transmit pain from the TrPs. ${ }^{[32]}$

Injection of a local anesthetic is one of the most effective treatment options available and is cited repeatedly as a way of achieving optimal results. The use of a local anesthetic is more comfortable for many patients and results in a longer lasting reduction in MTrP pain. ${ }^{10]}$

Pulsed electromagnetic field (PEMF) stimulation is a form of alternative therapy that claims to treat disease by applying electromagnetic energy to the body. ${ }^{[33]}$ Among the reported therapeutic methods, the use of biophysical interventions, such as PEMF therapy, has attracted the attention of clinicians in recent years, because of their noninvasive characteristics. ${ }^{[34,35]}$ It was observed that PEMF may affect tissue healing through a primary effect on vascular growth therefore has a role in stimulation of the healing process. ${ }^{\mid 36-38]}$

Although MTrPs are a widely recognized phenomenon in clinical practice, much remains to be elucidated with regarding their pathophysiology, mechanisms of pain referral, and treatment of choice. Hence, this study aimed to examine the effect of the four most common treatment modalities used to treat pain associated with MPDS through their direct effect on MTrPs.

\section{PATIENTS AND METHODS}

\section{Patients}

We enrolled 72 patients, from the outpatient clinic of the Oral and Maxillofacial Surgery Department, Faculty of Oral and Dental Medicine, Cairo University, Egypt. They were 57 females and 15 males aged 18-42 years (average 30 years), all with active MTrPs of the masseter muscle. The review board of Cario University approved this study.

General inclusion criteria were:

- Diagnosis of temporomandibular disorder

- Aged $>18$ years

- Musculoskeletal dysfunction

- Pain impairment

- The presence of a TrPs characterized by spontaneous pain of the right or left masseter muscle

- Restricted range of mouth opening

- No previous surgery in the temporomandibular region

- No other morbid conditions in the temporomandibular region as rheumatic diseases, or neurological diseases.

In addition, each patient had to fulfill the following criteria (according to the Helkimo index) ${ }^{[39]}$

- Slightly impairment of movement (index Dil)

- Moderate dysfunction = Dill

- Muscle pain sensitivity to pressure in four places (severe disorder)
- Pain associated with two or more movements (severe disorder)

- Sensitivity to posterior pressure (severe disorder).

\section{Methods}

The patients were divided randomly into four groups with each comprising 18 patients.

\section{Treatments}

Group I (low-level laser)

After locating of MTrP LLLT (wavelength $980 \mathrm{~nm}$, power 0.2 $\mathrm{W}$, total energy $12 \mathrm{~J}$ ) was applied using a fiber probe over the TrPs in a circular movement for $50 \mathrm{~s}$. In this group, each patient received LLLT 3 times per week for 4 weeks.

\section{Group II (dry needling)}

Each TrPs was marked clearly and the skin prepared and cleansed. The overlying skin was held between the thumb and index finger. It was then punctured with a dry needle. In this group, each patient received three sessions per week for 4 weeks, each session lasting $50 \mathrm{~s}$.

\section{Group III (anesthesia)}

Each TrPs was injected with $0.5 \mathrm{ml}$ mepivacaine 3\% local anesthetic solution. In this group, the injections were given 3 times per week for 4 weeks, using a standard dental syringe and 27-gauge needle.

\section{Group IV: (pulsed electromagnetic field)}

Each TrPs was exposed to (PEMF) stimulation. In this group, each patient received three sessions per week for 4 weeks, each session lasting $50 \mathrm{~min}$.

\section{Clinical examination}

The masseter muscle was located by a flat palpation technique, using one index finger. The masseter muscle was examined by means of palpation to determine:

- A palpable taut band

- A hypersensitive area within the taut band

- Pain felt by the patient when pressure was applied to the sensitive area (identifying an active TrPs)

- Repetition of a referred pain sensation upon stimulation of the area

- The occurrence of a LTR upon sharp palpation of the taut band.

Each patient pointed to the exact location of the pain and rated the pain (on a visual analog scale [VAS]) from 0 to 10 with 0 corresponding to no pain and 10 correspond to the worst pain. This information was recorded on the patient's chart. The pain was evaluated preoperatively and after 1 month, 2 months, and 3 months respectively from the start of treatment.

Assessment of painless maximum mouth opening (MMO) was performed by measuring the distance (in $\mathrm{mm}$ ) between the edges of the upper and lower central incisors using a Vernier graduated caliper. 
No other therapies were used. The patients were asked to stop taking other pain medications and receiving other therapies. Cetal (paracetmol $500 \mathrm{mg}$ [micronized] tablets, Egyptian International Pharmaceutical Industries Co., Cairo, Egypt) was prescribed as a pain killer only as required.

Evaluation of four groups was performed at six stages: prior to the treatment, after 2 weeks (mid-treatment), after 4 weeks (end of treatment), and monthly thereafter for 3 months.

The data regarding the pain scores were presented as mean \pm standard deviation values. For the pain scores and percentage changes in different variables, the data showed a nonparametric distribution; therefore, the Mann-Whitney $U$-test (a nonparametric alternative to the Student's $t$-test) was used to compare the two groups. The Wilcoxon signed-rank test (a nonparametric alternative to the paired $t$-test) was used to study the changes in mean pain scores over time.

The MMO data showed parametric distribution; therefore, the Student's t-test was used to compare the two groups. In addition, the paired $t$-test was also used to study the changes in MMO observations over time.

The significance level was set at $P \leq 0.05$. Statistical analysis was performed using IBM $^{\circledR} \quad$ SPSS $^{*}$ statistics version 20 (IBM Corporation, NY, USA).

\section{RESULTS}

\section{Pain}

Preoperatively: there was no statistically significant difference between pain scores in Groups I and II; although both showed statistically significantly lower mean scores. Furthermore, there was no statistically significant difference between pain scores in Groups III and IV, both showed statistically significant higher mean scores.

After 2 weeks, Group I showed a statistically significant higher mean score. There was no statistically significant difference between pain scores in Groups II and III; both showed lower mean scores. Group IV showed a statistically significantly lowest mean score.

After 3 months, Group I showed a statistically significantly highest mean score, followed by Group II and then Group III. Group IV showed a statistically significantly lowest mean score [Table 1].

For all time periods: in Groups I and II, there was nonstatistically significant decrease in mean pain scores. In Groups III and IV, there was a statistically significant lower mean pain scores [Table 2].

The percentage change was calculated as:

$\underline{\text { (Preoperative score) }- \text { (Postoperative score) }} \times 100$
After 2 weeks and after 3 months: there was no statistically significant difference between percentage reduction in pain scores of Groups III and IV; both showed a statistically significantly highest mean percentage reduction in pain scores. There was no statistically significant difference between percentage reduction in pain scores of Groups I and II; both showed a statistically significantly lowest mean percentage reduction in pain scores [Table 3].

For all time periods: there was no statistically significant difference between pain scores in Groups I and II; both showed statistically significant higher mean scores. There was no statistically significant difference between pain scores in Groups III and IV; both showed statistically significant lowest mean scores [Table 4].

In Group I, there was nonstatistically significant reduction in mean pain scores for all time periods.

In Group II, there was nonsignificant reduction in mean pain scores after 2 weeks, and a statistically significant reduction in mean pain scores after 3 months.

In Groups III and IV, there was a statistically significant reduction in mean pain scores for all time periods [Table 5].

The percentage change was calculated as before.

After 2 weeks and after 3 months: there was no statistically significant difference between percentage reduction in

Table 1: The mean, SD values and results of KruskalWallis test for comparison between pain scores (at rest) in the four groups

\begin{tabular}{|c|c|c|c|c|}
\hline \multirow{2}{*}{$\begin{array}{l}\text { Time } \\
\text { period }\end{array}$} & Group I & Group II & Group III & Group IV $P$ value \\
\hline & Mean SD & Mean SD & Mean SD & Mean SD \\
\hline
\end{tabular}

$\begin{array}{llllllllll}\text { Preoperative } & 4.7^{\mathrm{b}} & 3.3 & 3.7^{\mathrm{b}} & 2.7 & 6.6^{\mathrm{a}} & 2.5 & 6.4^{\mathrm{a}} & 2.7 & 0.008^{*}\end{array}$

$\begin{array}{llllllllll}2 \text { weeks } & 4.4^{\mathrm{a}} & 1.7 & 3.4^{\mathrm{b}} & 3 & 2.8^{\mathrm{b}} & 2.8 & 1.8^{\mathrm{c}} & 2 & 0.034^{*}\end{array}$

$\begin{array}{llllllllll}3 \text { months } & 4.1^{\mathrm{a}} & 2.9 & 2.9^{\mathrm{b}} & 3.1 & 1.8^{\mathrm{c}} & 2.2 & 1^{\mathrm{c}} & 1.7 & 0.008^{*}\end{array}$

*Significant at $P \leq 0.05$, different letters are statistically significantly different according to Mann-Whitney U-test. SD: Standard deviation

Table 2: The mean differences, SD values and results of Wilcoxon signed-rank test for the changes by time in mean pain scores (at rest) of each group

\begin{tabular}{llccc}
\hline Group & Time period & $\begin{array}{c}\text { Mean } \\
\text { difference }\end{array}$ & SD & P value \\
\hline I & Preoperative to 2 weeks & -0.3 & 3.4 & 0.574 \\
II $\quad$ Preoperative to 3 months & -0.6 & 3.9 & 0.607 \\
& Preoperative to 2 weeks & -0.3 & 2.4 & 0.623 \\
III $\quad$ Preoperative to 3 months & -0.9 & 3.9 & 0.327 \\
& Preoperative to 2 weeks & -3.8 & 2.4 & $0.003^{*}$ \\
IV $\quad$ Preoperative to 3 months & -4.8 & 2.4 & $0.003^{*}$ \\
& Preoperative to 2 weeks & -4.6 & 2.9 & $0.001^{*}$ \\
& Preoperative to 3 months & -5.4 & 3.2 & $0.001^{*}$ \\
\hline *Significant at PS0.05. SD: Standard deviation & &
\end{tabular}


Table 3: The mean percentage, SD values and results of Kruskal-Wallis test for comparison between percentage decrease in pain scores (at rest) in the four groups

\begin{tabular}{|c|c|c|c|c|c|c|c|c|c|}
\hline \multirow[t]{2}{*}{ Time period } & \multicolumn{2}{|c|}{ Group I } & \multicolumn{2}{|c|}{ Group II } & \multicolumn{2}{|c|}{ Group III } & \multicolumn{2}{|c|}{ Group IV } & \multirow[t]{2}{*}{$P$ value } \\
\hline & Mean & SD & Mean & SD & Mean & SD & Mean & SD & \\
\hline Preoperative to 2 weeks & $-8.2^{b}$ & 13.5 & $-7.3^{\mathrm{b}}$ & 5.9 & $-56.6^{a}$ & 38.8 & $-62.2^{\mathrm{a}}$ & 37.8 & $0.001^{*}$ \\
\hline Preoperative to 3 months & $-4.9^{b}$ & 19.7 & $-5.8^{b}$ & 13.4 & $-69.3^{a}$ & 35.5 & $-72.8^{a}$ & 40.2 & $0.004^{*}$ \\
\hline
\end{tabular}

*Significant at $P \leq 0.05$, different letters are statistically significantly different according to Mann-Whitney U-test. SD: Standard deviation

Table 4: The mean, SD values and results of KruskalWallis test for comparison between pain scores (PPT) in the four groups

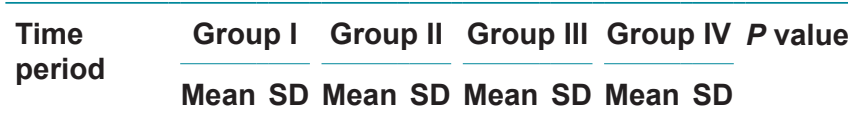

$\begin{array}{llllllllll}\text { Preoperative } & 9.1^{\mathrm{a}} & 0.9 & 8.9^{\mathrm{a}} & 1.3 & 7.8^{\mathrm{b}} & 1.2 & 7.9^{\mathrm{b}} & 1.2 & 0.008^{*}\end{array}$

2 weeks $\quad \begin{array}{llllllllll}7.4^{\mathrm{a}} & 2.4 & 8.1^{\mathrm{a}} & 2 & 3.4^{\mathrm{b}} & 2.9 & 3.2^{\mathrm{b}} & 2.3<0.001^{*}\end{array}$

$\begin{array}{llllllllll}3 \text { months } \quad 8^{\mathrm{a}} & 2.3 & 6.4^{\mathrm{a}} & 2.8 & 2.1^{\mathrm{b}} & 2.4 & 1.2^{\mathrm{b}} & 1.9<0.001^{*}\end{array}$

*Significant at $P \leq 0.05$, different letters are statistically significantly different according to Mann-Whitney U-test. SD: Standard deviation, PPT: Pain-pressure threshold

Table 5: The mean differences, SD values and results of Wilcoxon signed-rank test for the changes by time in mean pain scores (PPT) of each group

\begin{tabular}{llccc}
\hline Group & Time period & Mean difference & SD & $\boldsymbol{P}$ value \\
\hline I & Preoperative to 2 weeks & -1.6 & 2.6 & 0.055 \\
& Preoperative to 3 months & -1.1 & 2.2 & 0.095 \\
II $\quad$ Preoperative to 2 weeks & -0.7 & 1.8 & 0.131 \\
& Preoperative to 3 months & -2.4 & 2.5 & $0.008^{*}$ \\
III $\quad$ Preoperative to 2 weeks & -4.3 & 2.6 & $0.002^{*}$ \\
& Preoperative to 3 months & -5.7 & 2.3 & $0.002^{*}$ \\
IV $\quad$ Preoperative to 2 weeks & -4.7 & 2.6 & $<0.001^{*}$ \\
& Preoperative to 3 months & -6.7 & 2.4 & $<0.001^{*}$
\end{tabular}

*Significant at $P \leq 0.05$. SD: Standard deviation, PPT: Pain-pressure threshold

pain scores of Groups III and IV; both showed a statistically significantly highest mean percentage reduction in pain scores. There was no statistically significant difference between percentage reduction in pain scores of Groups I and II; both showed a statistically significant mean percentage reduction in pain scores [Table 6].

\section{Maximum mouth opening}

Preoperatively and after 2 weeks: there was no statistically significant difference in MMO between the four groups.

After 3 months: Group IV showed a statistically significant highest mean MMO. There was no statistically significant difference between Groups I-III; all showed the statistically significantly lowest mean scores [Table 7].

In Groups I and II, there was no statistically significant change in mean MMO for all the time periods.

In Groups III and IV, there was a statistically significant increase in mean MMO for all time periods [Table 8].
The percentage change was calculated before.

For all time periods: there was no statistically significant difference between the four groups [Table 9].

\section{DISCUSSION}

Temporomandibular pain of myofascial origin is a condition that is often referred to outpatient clinics of Oral and Maxillofacial Surgery Department. In this study, the highest proportion of patients with TMJD is among women aged 21-30 years. One explanation for higher prevalence is that women have lower levels of muscle strength under stress than men.

The use of noninvasive and costless methods of treatment with reduced morbidity is our aim. The standard way of treating temporomandibular myofascial pain in our hospital is to use a combination of pharmacologic and splint therapy, which produces temporary relief. However, pharmacologic treatments quickly reach the limit of therapeutic efficacy and they are also associated with side effects (e.g., gastrointestinal disorders, drug interactions, and adverse reactions), so research is currently focused on the search for alternative treatments.

Active exercise, manual therapy, postural training, and relaxation techniques, may decrease pain and increase overall vertical mouth opening. The characteristics of TMJD, however, remain highly debated as its hallmark findings of taut bands (localized areas of increased muscle tone and tenderness) and TrPs (smaller areas of increased tenderness within the bands that produce referred pain on pressure) depend on the clinician's skills at identification.

The identification of taut bands and TrPs is important not only for diagnosis, but also for potential treatment. We believe that pain from TMJD is better expressed by the participant themself, so patients are required to self-evaluate their pain as: nonexistent, mild, moderate, severe and very severe, using a VAS.

Trigger points also appear to have a positive effect on pain, releasing a TrPs through ischemic spots reduction, which results in reduced pain. Active MTrPs act as major peripheral pain generators for regional and generalized musculoskeletal pain conditions. 
Table 6: The mean percentage, SD values and results of Kruskal-Wallis test for comparison between percentage decrease in pain scores (PPT) in the four groups

\begin{tabular}{|c|c|c|c|c|c|c|c|c|c|}
\hline \multirow[t]{2}{*}{ Time period } & \multicolumn{2}{|c|}{ Group I } & \multicolumn{2}{|c|}{ Group II } & \multicolumn{2}{|c|}{ Group III } & \multicolumn{2}{|c|}{ Group IV } & \multirow[t]{2}{*}{$P$ value } \\
\hline & Mean & SD & Mean & SD & Mean & SD & Mean & SD & \\
\hline Preoperative to 2 weeks & $-17^{b}$ & 27.7 & $-7.3^{b}$ & 14.1 & $-57.6^{a}$ & 35.1 & $-58.7^{a}$ & 30.9 & $<0.001^{*}$ \\
\hline Preoperative to 3 months & $-11.6^{b}$ & 25.6 & $-27.8^{b}$ & 29.7 & $-74.1^{a}$ & 30.5 & $-83.3^{a}$ & 28.2 & $<0.001^{*}$ \\
\hline
\end{tabular}

*Significant at $P \leq 0.05$, different letters are statistically significantly different according to Mann-Whitney U-test. SD: Standard deviation, PPT: Pressure-pain threshold

Table 7: The mean, SD values and results of one-way ANOVA test for comparison between (MMO) in the four groups

\begin{tabular}{|c|c|c|c|c|c|c|c|c|c|}
\hline \multirow{2}{*}{$\begin{array}{l}\text { Time } \\
\text { period }\end{array}$} & \multicolumn{2}{|c|}{ Group I } & \multicolumn{2}{|c|}{ Group II } & \multicolumn{2}{|c|}{ Group III } & \multicolumn{2}{|c|}{ Group IV } & \multirow[t]{2}{*}{$P$ value } \\
\hline & Mean & SD & Mean & SD & Mean & SD & Mean & SD & \\
\hline Preoperative & 36.2 & 6.8 & 35.6 & 5.5 & 34.6 & 2.4 & 35.7 & 9.4 & 0.958 \\
\hline 2 weeks & 37.6 & 4.9 & 37.1 & 4.4 & 36.6 & 1.4 & 40 & 5.6 & 0.376 \\
\hline 3 months & $35^{b}$ & 3.8 & $36^{b}$ & 4.2 & $36.8^{b}$ & 1.2 & $40.1^{\mathrm{a}}$ & 5.3 & $0.050^{*}$ \\
\hline
\end{tabular}

Table 8: The mean differences, SD values and results of paired $t$-test for the changes by time in mean (MMO) of each group

\begin{tabular}{llccc}
\hline Group & Time period & $\begin{array}{c}\text { Mean } \\
\text { difference }\end{array}$ & SD & $\boldsymbol{P}$ value \\
\hline I & Preoperative to 2 weeks & 1.3 & 4.6 & 0.413 \\
& Preoperative to 3 months & -1.2 & 6.7 & 0.598 \\
II & Preoperative to 2 weeks & 1.6 & 6.9 & 0.518 \\
& Preoperative to 3 months & 0.4 & 7.1 & 0.857 \\
III & Preoperative to 2 weeks & 2 & 1.9 & $0.015^{*}$ \\
& Preoperative to 3 months & 2.2 & 1.8 & $0.007^{*}$ \\
IV $\quad$ Preoperative to 2 weeks & 4.3 & 7 & $<0.001^{*}$ \\
& Preoperative to 3 months & 4.4 & 7.2 & $<0.001^{*}$ \\
\hline
\end{tabular}

*Significant at $P \leq 0.05$. SD: Standard deviation, MMO: Maximum mouth opening

Masseter muscle was selected a model for testing therapeutic modalities in our study, because masseter muscle taut bands are more superficial making them easily distinguishable and subsequently more sensitive to the external effects of PEMF therapy.

As hypertonic shortened mandible elevators (masseter) limit temporomandibular range of motion, therefore this hypothetically allows for greater range of motion to decrease tension in these muscles.

Recent evidence in understanding the pathophysiology of MTrPs agree that local pain and tenderness at MTrPs may be intrinsic part of muscle ischemia associated with sustained focal muscle contraction and/or muscle cramps. Massage techniques seem to be more effective when applied to superficial muscles than when applied to masseter muscles.
Similar results were found in the study by Thomas et al. ${ }^{[40]}$ who reported that a reduction in muscular pain could be achieved using a portable PEMF device. We believe that direct applications of PEMFs lead to masseter muscle massage (focal muscle fiber contraction), which aside from a heating effect have had the greatest impact on pain relief.

The results indicate that exposure to a specific low-frequency PEMF appears to exert some beneficial analgesic effects, particularly in patients with TMJD and should be used as an adjunctive treatment with other therapies.

Laser therapy induced a reduction in pain symptoms after application and increased patient's range of mouth opening. The reduction in muscle pain between the first and last session in this study; showed the difference between laser and PEMF therapies, with PEMF treatment controlling pain more efficiently. Laser treatment is a supportive therapy that is effective at treating patients with TMJD and relieving pain symptoms without changing the etiology of the disorder, so that successful treatment can be achieved in the long term.

For MTrPs injection is an effective technique for providing high pressure stimulation. High pressure stimulates mechanoceptors to modulate pain. One injection is often not sufficient to relieve pain, so several injections may be required. TrPs muscle injection provides an immediate way to relieve pain at its source, although it has a short-term effect; however in conjunction with supporting therapies, it is considered to be an effective, inexpensive and easy treatment option.

In this study, the technique used was to quickly insert, the needle tip into a point within the MTrP region, the rapid movement of the tiny tipped needle can provoke strong stimulation. Strong stimuli applied to the sensitive nociceptors can generate strong impulses, and these impulses are transmitted to the spinal cord. It is likely that these impulses can subsequently break the negative cycle in which the neural circuit is responsible for the MTrPs (the hypothetical "MTrP circuit")|38| in a manner similar to hyperstimulation analgesia. This is probably the mechanism for remote pain control as described in this study. 
Table 9: The mean percentage, SD values and results of Kruskal-Wallis test for comparison between percentage changes in (MMO) in the four groups

\begin{tabular}{|c|c|c|c|c|c|c|c|c|c|}
\hline \multirow[t]{2}{*}{ Time period } & \multicolumn{2}{|c|}{ Group I } & \multicolumn{2}{|c|}{ Group II } & \multicolumn{2}{|c|}{ Group III } & \multicolumn{2}{|c|}{ Group IV } & \multirow[t]{2}{*}{$P$ value } \\
\hline & Mean & SD & Mean & SD & Mean & SD & Mean & SD & \\
\hline Preoperative to 2 weeks & 5.7 & 15.7 & 7.1 & 11.7 & 6.1 & 6.1 & 18.1 & 32.4 & 0.736 \\
\hline Preoperative to 3 months & -0.3 & 3.4 & 4 & 5.2 & 6.7 & 5.9 & 18.7 & 33.6 & 0.132 \\
\hline
\end{tabular}

SD: Standard deviation, MMO: Maximum mouth opening

\section{CONCLUSION}

Our findings suggest that PEMF is the most effective treatment for alleviating pain and improving mouth range of motion in patients with myofascial pain dysfunction. However, in spite of its effect on reducing pain and improving range of mouth opening, we couldn't rely on this treatment method alone for patients with TMJD. Rather it should be used as an adjunctive treatment with other therapies, such as splint therapy or arthrocentesis.

\section{REFERENCES}

I. Hong CZ, Hsueh TC. Difference in pain relief after trigger point injections in myofascial pain patients with and without fibromyalgia. Arch Phys Med Rehabil 1996;77:1 | 61-6.

2. Haddad DS, Brioschi ML, Arita ES.Thermographic and clinical correlation of myofascial trigger points in the masticatory muscles. Dentomaxillofac Radiol 2012;41:62I-9.

3. Kamanli A, Kaya A,Ardicoglu O, Ozgocmen S, Zengin FO, BayikY. Comparison of lidocaine injection, botulinum toxin injection, and dry needling to trigger points in myofascial pain syndrome. Rheumatol Int 2005;25:604-II.

4. Fernández-de-las-Peñas C, Dommerholt J. Myofascial trigger points: peripheral or central phenomenon? Curr Rheumatol Rep 2014;16:395.

5. Celik D, Mutlu EK. Clinical implication of latent myofascial trigger point. Curr Pain Headache Rep 2013;17:353.

6. McMillan AS, Blasberg B. Pain-pressure threshold in painful jaw muscles following trigger point injection.J Orofac Pain 1994;8:384-90.

7. Simons DG, Travell JG, Simons LS. Travell and Simons' Myofascial Pain and Dysfunction: the Trigger Point Manual. $2^{\text {nd }}$ ed. Baltimore: Williams andWilkins; 1999.

8. Ling FW, Slocumb JC. Use of trigger point injections in chronic pelvic pain. Obstet Gynecol Clin North Am 1993;20:809-I5.

9. Hopwood MB, Abram SE. Factors associated with failure of trigger point injections. Clin J Pain 1994; 10:227-34.

10. Han SC, Harrison P.Myofascial pain syndrome and trigger-point management. Reg Anesth 1997;22:89-101.

II. Demirkol N, Sari F, Bulbul M, Demirkol M, Simsek I, Usumez A. Effectiveness of occlusal splints and low-level laser therapy on myofascial pain. Lasers Med Sci 2014; DOI: 10.1007/s 10103-014-1522-7.

12. Gerwin RD, Dommerholt J. Treatment of myofascial pain syndromes. In: Weiner R, editor. Pain Management; a Practical Guide for Clinicians. Boca Raton: CRC Press; 2002. p. 235-49.

13. Imamura ST, Fischer AA, Imamura M, Teixeira MJ, Lin TY, Kaziyama HS. Pain management using myofascial approach when other treatment failed. Phys Med Rehabil Clin North Am 1997;8: 179-96.

14. Thorsen H, Gam AN, Svensson BH, Jess M, Jensen MK, Piculell I, Schack LK, Skjøtt K. Low level laser therapy for myofascial pain in the neck and shoulder girdle. A double-blind, cross-over study. Scand J Rheumatol 1992;21:139-4I.

15. Kamyszek G, Ketcham R, Garcia R Jr, Radke J. Electromyographic evidence of reduced muscle activity when ULF-TENS is applied to the $\mathrm{V}^{\text {th }}$ and $\mathrm{VII}{ }^{\text {th }}$ cranial nerves. Cranio 2001;19:162-8.

16. Hong CZ. Considerations and recommendations regarding myofascial trigger point injection.J Musculoskelet Pain 1994;2:29-59.
17. Venancio Rde A, Camparis CM, Lizarelli Rde F. Low intensity laser therapy in the treatment of temporomandibular disorders: a double-blind study.J Oral Rehabil 2005;32:800-7.

18. Núñez SC, GarcezAS, Suzuki SS, Ribeiro MS. Management of mouth opening in patients with temporomandibular disorders through low-level laser therapy and transcutaneous electrical neural stimulation. Photomed Laser Surg 2006;24:45-9.

19. Dundar U, Eucik D, Samli F. The effect of gallium arsenide aluminum laser therapy in the treatment of temporomandibular joint disorders.J Clin Rhematol 2006;33:229-35.

20. Thornton AL, McCarty CW, Burgess MJ. Effectiveness of low-level laser therapy combined with an exercise program to reduce pain and increase function in adults with shoulder pain:a critically appraised topic.J Sport Rehabil 2013;22:72-8.

21. Kerstein RL, Lister T, Cole R. Laser therapy and photosensitive medication: a review of the evidence. Lasers Med Sci 2014; DOI:10.1007/sI0I03-0I41553-0.

22. Sattayut S, Trivibulwanich J, Pipithirunkarn N, Danvirutai N.A clinical efficacy of using $\mathrm{CO} 2$ laser irradiating to transparent gel on aphthous stomatitis patients. Laser Ther 20। 3;22:283-9.

23. MikhailovVA, Scobelkin OK, Denisov IN, Frank GA, Voltohenko NN. Results of treatment in patients with IIA-IIIA st. breast cancer treated by combination of low level laser therapy [LLLT] and surgery [5-year experience]. SPIE 1996;2728:83-9|.

24. Taradaj J, Halski T, Kucharzewski M, Urbanek T, Halska U, Kucio C. Effect of laser irradiation at different wavelengths $(940,808$, and $658 \mathrm{~nm})$ on pressure ulcer healing: results from a clinical study. Evid Based Complement Alternat Med 2013;2013:960240.

25. Soriano F. The analgesic effect of $904 \mathrm{~nm}$ gallium arsenide semiconductor low level laser therapy on osteoarticular pain, a report on 938 irradiated patients. LaserTher 1995;7:75.

26. Bülow PM, Jensen H, Danneskiold-Samsøe B. Low power Ga-Al-As laser treatment of painful osteoarthritis of the knee. A double-blind placebo-controlled study. Scand J Rehabil Med 1994;26:155-9.

27. Basford JR, Malanga GA, Krause DA, Harmsen WS. A randomized controlled evaluation of low-intensity laser therapy: plantar fasciitis. Arch Phys Med Rehabil 1998;79:249-54.

28. Kato MT, Kogawa EM, Santos CN, Conti PC. TENS and low-level laser therapy in the management of temporomandibular disorders. J Appl Oral Sci $2006 ; 14: 130-5$.

29. Kulekcioglu S, Sivrioglu K, Ozcan O, Parlak M. Effectiveness of low-level laser therapy in temporomandibular disorder. Scand J Rheumatol 2003;32: I 14-8.

30. Fikácková H, Dostálová T,Vosická R, Peterová V, Navrátil L, LesákJ. Arthralgia of the temporomandibular joint and low-level laser therapy. Photomed Laser Surg 2006;24:522-7.

31. Rayegani SM, Bayat M, Bahrami MH, Raeissadat SA, Kargozar E. Comparison of dry needling and physiotherapy in treatment of myofascial pain syndrome. Clin Rheumatol 20I3; DOI:I0.1007/s 10067-0I3-2448-3.

32. Delle Monache S, Angelucci A, Sanità P, lorio R, Bennato F, Mancini F, Gualtieri G, Colonna RC. Inhibition of angiogenesis mediated by extremely low-frequency magnetic fields (ELF-MFs). PLOS One 2013;8:e79309.

33. Chao EY, Inoue N. Biophysical stimulation of bone fracture repair, regeneration and remodelling. Eur Cell Mater 2003;6:72-84.

34. Shi HF, CheungWH, Qin L, LeungAH, Leung KS. Low-magnitude high-frequency vibration treatment augments fracture healing in ovariectomy-induced osteoporotic bone. Bone 2010;46:1299-305.

35. Martino CF, Perea H, Hopfner U, Ferguson VL, Wintermantel E. Effects 
of weak static magnetic fields on endothelial cells. Bioelectromagnetics 2010;31:296-301.

36. Roland D, Ferder M, Kothuru R, Faierman T, Strauch B. Effects of pulsed magnetic energy on a microsurgically transferred vessel. Plast Reconstr Surg 2000; | 05: | 37|-4.

37. Smith TL, Wong-Gibbons D, Maultsby J. Microcirculatory effects of pulsed electromagnetic fields. J Orthop Res 2004;22:80-4

38. Cummings TM,WhiteAR. Needling therapies in the management of myofascial trigger point pain: a systematic review. Arch Phys Med Rehabil 200 I;82:986-92

39. Helkimo M. Studies on function and dysfunction of the masticatory system. II. Index for anamnestic and clinical dysfunction and occlusal state. Sven Tandlak Tidskr 1974;67:101-2I.
40. Thomas AW, Graham K, Prato FS, McKay J, Forster PM, Moulin DE, Chari S. A randomized, double-blind, placebo-controlled clinical trial using a low-frequency magnetic field in the treatment of musculoskeletal chronic pain. Pain Res Manag 2007; 1 2:249-58.

How to cite this article: Fouda A. Comparison between four treatment modalities for active myofascial triggers points. Plast Aesthet Res 2014;1:21-8.

Source of Support: Nil, Conflict of Interest: None declared.

Received: 24-02-2014; Accepted: 19-05-2014 